\title{
ПОРАЖЕНИЯ СЕРДЕЧНО-СОСУДИСТОЙ СИСТЕМЫ У ПАЦИЕНТОВ С САХАРНЫМ ДИАБЕТОМ 2 ТИПА
}

\author{
Гагарин В.И., Дмитриева Н.Г., Мохначевская Л.П., Костыгова В.А. \\ ГАУРС (Я) «Республиканская клиническая больница № 3», Якутск
}

Сахарный диабет (СД) в Республике Саха (Якутия) в настоящее время является самой распространенной патологией эндокринной системы, особенно, у лиц пожилого и старческого возраста.

ЦЕЛЬ: изучить поражение сердечно-сосудистой системы у больных сахарным диабетом (СД) 2 типа, особенно у лиц пожилого и старческого возраста, по материалам стационара № 1 ГБУ РС (Я) «РБ № 3» M3 PC (Я)

МАТЕРИАЛЫ И МЕТОДЫ: С целью Решения поставленной цели, в исследовании были включены 90 пациентов (49 женщин и 41 мужчин) с СД 2 типа в возрасте от 35 до 90 лет, прошедших стационарное лечение в лечебно-реабилитационном центре ГАУ РС(Я) «РКБ № №» за 2018 г. Возраст пациентов колебался от 35 до 90 лет. Все пациенты проходили полное клиническое и лабораторно-инструментальное исследование, выясняли наследственную отягощенность по СД. В динамике измеряли гликемию натощак и постпрандиальную гликемию, по показаниям оценивали гликемический профиль, в динамике контролировали уровень гликированного гемоглобина $\left(\mathrm{HBA}_{1 c}\right)$. Проводили биохимические анализы, отражающие функциональное состояние печени, поджелудочной железы, почек, оценивали состояние глазного дна.

РЕЗУЛЬТАТЫ: нами проведено клинико-лабораторно-инструментальное исследование 90 пациентов СД 2 типа, среди которых 56,7\% женщин и 43,3\% мужчин. Жителей сельских местностей среди них 31,2\% и городских - 68,8\%. На диспансерном учете состоит 79 пациентов $(87,7 \%)$. Нами констатированы следующие поражения сердечно-сосудистой системы: ишемическая болезнь сердца у 32 пациентов (35,6\%), нарушение ритма сердца у 21 больных (23,3\%), ПИКС у 18 (20,0\%). OHМК у 14 (15,6\%). ТИА у 1 (1,1\%), ПИКС и ОНМК у 4 человек (4,4\%). Наибольшее количество сердечно-сосудистых осложнений наблюдалось у больных с декомпенсированным и субкомпенсированным СД 2 типа.

Клиническое течение СД 2 типа у лиц пожилого и старческого возраста часто осложняется обилием сочетанной полиорганной патологии. У 65-80\% пожилых пациентов имеются поражения сердечно-сосудистой системы, артериальная гипертония и дислипидемия, которые требуют обязательной коррекции лечения.

Таким образом, нами получены данные, представленные в обобщенном виде на фактическом материале (90 больных) о поражении сердечно-сосудистой системы у пациентов СД 2 типа.

Выводы: на основании полученных результатов можно сделать следующие выводы:

1. Клиническое течение СД 2 типа у лиц пожилого возраста сочетается поражением сердечно-сосудистой системы.

2. Поражения сердечно-сосудистой системы требуют медикаментозной коррекции.

3. Своевременное назначение инсулинотерапии снижает риск развития сердечно-сосудистых осложнений.

КЛЮЧЕВЫЕ СЛОВА: сахарный диабет 2 mипа; сердечно-сосудистая система; пожилой возраст. 